\title{
Bad Cholesterol or "Bad" Science?
}

\section{Daniele Naviglio*}

Department of Chemical Sciences, University of Naples Federico II, via Cintia 4, 80126 Naples, Italy

In a recent paper entitled: "Application of Rapid Sample Preparation Method and Monitoring for Cholesterol Content in Chicken Egg and Egg powder" [1], the Authors show that cholesterol content in Korean eggs ranges between 160 and $200 \mathrm{mg}$ per egg, with an average value of $180 \mathrm{mg} / \mathrm{egg}$. In this study, to analyse the cholesterol content of Korean eggs, Authors set up and used a different method from that we used previously [2]. Surprisingly (but not so much!), results from both studies were very similar, since we found an average value of 157 $\mathrm{mg} / \mathrm{egg}$ in the range of $120-193 \mathrm{mg} / \mathrm{egg}$. Notably, both studies indicate an average value inferior to values reported in previous literature that are 275 or $250 \mathrm{mg}$ per egg; moreover the newest experimentations indicate an interval in which cholesterol content ranges; by which, a first important point can be assessed: values of cholesterol content per egg reported in literature up to now, indicate just a single value without reporting changes in concentration. It means that statistically a subject can eat eggs with a cholesterol content ranging from $120 \mathrm{mg}$ per egg to a maximum of $200 \mathrm{mg}$ per egg; by the way, this content is lower than that indicated from American Heart Association of $250 \mathrm{mg} / \mathrm{egg}$.

In literature there are many papers describing that healthy subjects are invited to eat one or more eggs a day for three or four weeks, after that they are monitored for blood cholesterol level; importantly, it has been reported that, at the end of such protocol, the cholesterol blood content did not change [3]. The finding that the serum concentration of cholesterol is not increased (it is decreased in many cases!) in subjects upon eating several eggs for some weeks, strongly suggests that eating eggs, irrespective of their cholesterol content, is not necessarily causing an increase of serum concentration of cholesterol.

These results can be easily explained keeping in mind the feedback control production activated by enzymes: more cholesterol is introduced in the body by diet, minus endogenous cholesterol will be produced [4].

Alternatively, this result could be demonstrated mathematically making some calculation; the normal concentration of cholesterol content in blood is around $110 \mathrm{mg} / \mathrm{dl}$; assuming that a healthy male subject has about six liters of blood, the total quantity of cholesterol is $1.1 \mathrm{~g} / \mathrm{l} \times 6 \mathrm{l}=6.6$ grams. If we consider the assumption of two eggs having $250 \mathrm{mg}$ each of cholesterol and then the assumption of $500 \mathrm{mg}$ of cholesterol, the increasing of total circulating cholesterol will be: 6.6 $\mathrm{g}+0.5 \mathrm{~g}=7.1 \mathrm{~g}$. To calculate the new concentration of serum cholesterol we have to divide total cholesterol by total blood volume: $7.1 \mathrm{~g} / 6 \mathrm{l}=1.18$ $\mathrm{g} / \mathrm{l}$ equivalent to $118 \mathrm{mg} / \mathrm{dl}$. The increment in cholesterol quantity is
$(118-110) / 110 \times 100=7.3 \%$ ! It seems unbelievable that no one, including medical doctors, made this calculation for more than forty years!

In addition we have indications that during periods of war many people ate many eggs per day because of few resources, but no clear indications of increased deaths for cardiovascular diseases arise.

To note, avoiding the eating of eggs in order to avoid a high (?!) cholesterol dietary intake, implies a possible negative effect on health, considering that some other important and beneficial nutrients of eggs, such as ovoalbumins, vitamins, minerals could be poorly introduced in the body.

By the above consideration, in my opinion, a couple of important questions can be asked:

Is it still the case that medical doctors limit the assumption of eggs in the diet?

The history of eating few eggs in a week is linked to a bad cholesterol content or to a "bad" science?

\section{Notation}

I wrote this letter before publication of 2015 Dietary Guidelines of United States Department of Agriculture (USDA) [5].

The 2015 DGAC will not bring forward this recommendation because available evidence shows no appreciable relationship between consumption of dietary cholesterol and serum cholesterol, consistent with the conclusions of the AHA/ACC report. Cholesterol is not a nutrient of concern for overconsumption [6].

\section{References}

1. Jung-Min P, In-Seek J, Byung-Man K, Jang-Hyuk A, Donggil L, et al. (2013) Application of Rapid Sample Preparation Method and Monitoring for Cholesterol Content in Chicken Egg and Egg powder. Korean J Food Sci An 33: 672-677.

2. Naviglioa D, Galloa M, Grottagliea L, Scalaa C, Ferrarab L, et al. (2012) Determination of cholesterol in Italian chicken eggs. Food Chem 132: 701-708.

3. Rong Y, Chen L, Zhu T, Song Y, Yu M, et al. (2013) Egg consumption and risk of coronary heart disease and stroke: dose-response meta-analysis of prospective cohort studies. BMJ 346: e8539.

4. Fernandez ML (2012) Rethinking dietary cholesterol. Curr Opin Clin Nutr Metab Care 15: 117-121.

5. USDA (2015) Good News from USDA: 2015 Dietary Guidelines.

6. Scientific Report of the 2015 Dietary Guidelines Advisory Committee.
*Corresponding author: Daniele Naviglio, Department of Chemical Sciences, University of Naples Federico II, via Cintia 4, 80126 Naples, Italy, Tel: +390812539348; Fax: +390817754942; E-mail: naviglio@unina.it

Received January 14, 2016; Accepted January 21, 2016; Published January 23 2016

Citation: Naviglio D (2016) Bad Cholesterol or "Bad" Science? Med chem 6: 040 doi:10.4172/2161-0444.1000321

Copyright: () 2016 Naviglio D. This is an open-access article distributed under the terms of the Creative Commons Attribution License, which permits unrestricted use, distribution, and reproduction in any medium, provided the original author and source are credited. 